\title{
Article \\ Combining Yoga Exercise with Rehabilitation Improves Balance and Depression in Patients with Chronic Stroke: A Controlled Trial
}

\author{
Yen-Ting Lai ${ }^{1,2,3}$, Chien-Hung Lin ${ }^{4,5,6}$, City C. Hsieh ${ }^{7}$, Jung-Cheng Yang ${ }^{2,3}$, Han-Hsing Tsou ${ }^{8,9,10} \mathbb{D}$, \\ Chih-Ching Lin ${ }^{4,11}$, Szu-Yuan Li ${ }^{4,11}\left(\mathbb{D}\right.$, Hsiang-Lin Chan ${ }^{12,+}$ (D) and Wen-Sheng Liu $4,6,8,9,13,14, *,+$
}

Citation: Lai, Y.-T.; Lin, C.-H.; Hsieh, C.C.; Yang, J.-C.; Tsou, H.-H.; Lin,

C.-C.; Li, S.-Y.; Chan, H.-L.; Liu, W.-S Combining Yoga Exercise with Rehabilitation Improves Balance and Depression in Patients with Chronic Stroke: A Controlled Trial. Appl. Sci. 2022, 12, 922. https://doi.org/ 10.3390/app12020922

Academic Editors: Francesco Cappello and Magdalena Gorska-Ponikowska

Received: 1 December 2021 Accepted: 10 January 2022 Published: 17 January 2022

Publisher's Note: MDPI stays neutral with regard to jurisdictional claims in published maps and institutional affiliations.

Copyright: (C) 2022 by the authors. Licensee MDPI, Basel, Switzerland. This article is an open access article distributed under the terms and conditions of the Creative Commons Attribution (CC BY) license (https:// creativecommons.org/licenses/by/ $4.0 /)$.
1 Department of Physical Medicine and Rehabilitation, National Taiwan University College of Medicine, Taipei 100, Taiwan; csmclaiyt@gmail.com

2 Department of Physical Medicine and Rehabilitation, National Taiwan University Hospital Hsin-Chu Branch, Hsinchu 300, Taiwan; w3yjcw@gmail.com

3 Department of Physical Medicine and Rehabilitation, National Taiwan University Hsin-Chu Hospital, Hsinchu 300, Taiwan

4 Faculty of Medicine, School of Medicine, National Yang Ming Chiao Tung University, Hsinchu 300, Taiwan; chlin5@vghtpe.gov.tw (C.-H.L.); lincc2@vghtpe.gov.tw (C.-C.L.); syli@vghtpe.gov.tw (S.-Y.L.)

5 Department of Pediatrics, Taipei Veterans General Hospital, Taipei 112, Taiwan

6 College of Science and Engineering, Fu Jen Catholic University, New Taipei City 242, Taiwan

7 Department of Kinesiology, National Tsing Hua University, Hsinchu 300, Taiwan; chsieh@mail.nd.nthu.edu.tw

8 Institute of Food Safety and Health Risk Assessment, National Yang Ming Chiao Tung University, Taipei 112, Taiwan; hhtsou@nycu.edu.tw

9 Institute of Food Safety and Health Risk Assessment, National Yang-Ming University, Taipei 112, Taiwan

10 Kim Forest Enterprise Co., Ltd., New Taipei City 221, Taiwan

11 Division of Nephrology, Department of Medicine, Taipei Veterans General Hospital, Taipei 112, Taiwan

12 Department of Child Psychiatry, Chang Gung Memorial Hospital and University, Taoyuan 333, Taiwan; ivyhlin70@kimo.com

13 Division of Nephrology, Department of Medicine, Taipei City Hospital, Zhongxing Branch, Taipei 103, Taiwan

14 Departmentof Special Education, University of Taipei, Taipei 100, Taiwan

* Correspondence: dat23@tpech.gov.tw; Tel.: +886-2-979305704

+ These authors contributed equally to this manuscript.

\begin{abstract}
Background: We combined yoga with standard stroke rehabilitation and compared it to the rehabilitation alone for depression and balance in patients. Methods: Forty patients aged from 30 to 80 who had suffered a stroke 90 or more days previously were divided evenly with age stratification and patients' will (hence not randomized). In the intervention group 16 completed 8-week stroke rehabilitation combined with $1 \mathrm{~h}$ of yoga twice weekly. Another 19 patients completed the standard rehabilitation as the control group. Results: The yoga group showed significant improvement in depression (Taiwanese Depression Questionnaire, $p=0.002$ ) and balance (Berg Balance Scale, $p<0.001)$. However, the control group showed improvement only in balance $(p=0.001)$ but not in depression ( $p=0.181$ ). Further analysis showed both sexes benefitted in depression, but men had a greater improvement in balance than women. Depression in left-brain lesion patients improved more significantly than in those with right-brain lesion, whereas balance improved equally despite lesion site. For patients under or above the age of 60 , depression and balance both significantly improved after rehabilitation. Older age is significantly related to poor balance but not depression. Conclusions: Combining yoga with rehabilitation has the potential to improve depression and balance. Factors related to sex, brain lesion site and age may influence the differences.
\end{abstract}

Keywords: stroke; yoga; balance disability; depression 


\section{Introduction}

Stroke is highly prevalent in high-income countries (1015-1184 cases per 100,000 people in 2013) [1] Imbalance and post-stroke depression are common among stroke patients and may severely impair their activities of daily living [2,3]. The majority of stroke patients (around $83 \%$ ) had a balance disability [4]. In a meta-analysis, the percentage of post-stroke depression was about 31\% [5], and depression is associated with falls and negatively correlated with functional status [6]. The risk of falls for stroke patients is 1.77 times compared to healthy adults so post-stroke rehabilitation is essential [7].

Exercise increases serotonin which works against depression [8]. Carek et al. reported both aerobic and anaerobic exercises are effective [9]. Increased exercise frequency and group therapy seem be beneficial [10]. The practice of exercises promotes improvements in the levels of depression in people who suffered an ischemic stroke [11]. Franklin et al. reported yoga practices might be also protective [12]. Yoga is widely integrated into physical therapies [13]. However, few reports have focused on the impact of yoga in stroke patients [14-16]. Yoga can lower blood pressure, serum cholesterol and increase in internal reasons for exercise [17,18]. Furthermore, yoga consists of dynamic/static postures to stretch muscles and joints, and improve balance and coordination [19]. Bastille and Gill-Body [14] reported an 8-week intervention (1.5-h yoga sessions two times per week) for patients with chronic post-stroke hemiparesis improved balance. Chronic stroke is defined as the condition 90 days after stroke [20]. About $95 \%$ of patients achieved their best neurological recovery within 11 weeks, while minor stroke related to faster recovery [21].

Previous studies enrolled patients who began yoga "after" completing the post stroke rehabilitation program. However, no study focused combining yoga into a standard rehabilitation. We compared depression and balance among chronic stroke patients who underwent combining yoga and standard rehabilitation and those with standard rehabilitation alone.

\section{Materials and Methods}

\subsection{Ethic Statement}

Institutional Review Board (IRB)/Ethics Committee approval was obtained before the trial began, and the study was conducted in full compliance with the Declaration of Helsinki. The study was approved by the Ethics Committee of National Taiwan University Hospital Hsin-Chu Branch, 201210006IRB. All written consents were obtained from study participants. Clinical Trial Registration Information: Yoga Exercise for Improving Balance in Patients with Subacute and Chronic Stroke, NCT01806922. URL: https:/ / clinicaltrials. gov / ct2/show / NCT01806922 (accessed on 11 February 2014).

\subsection{Inclusion and Exclusion Criteria}

The inclusion criteria: (1) Patients with stroke more then 90 days, (2) can stand independently for $1 \mathrm{~min}$, (3) aged from 30 to 80 years. Exclusion criteria: (1) Those under other therapy (such as acupuncture), (2) diagnosis of other psychiatric disease or use of a psychotropic agent, (3) difficult to follow instructions, and (4) other contraindications like cardiopulmonary disease.

\subsection{Protocol}

Between onset and enrollment, all patients received the same regular rehabilitation at our hospital. The participants were first stratified into several age groups (5 years apart), then divided each age group by half into the following two groups (first by their will and then by assignment). The intervention group was trained with $60 \mathrm{~min}$ of yoga exercise, two times per week, combined with standard stroke rehabilitation for 8 weeks. The control group only underwent standard rehabilitation (Figure 1). 


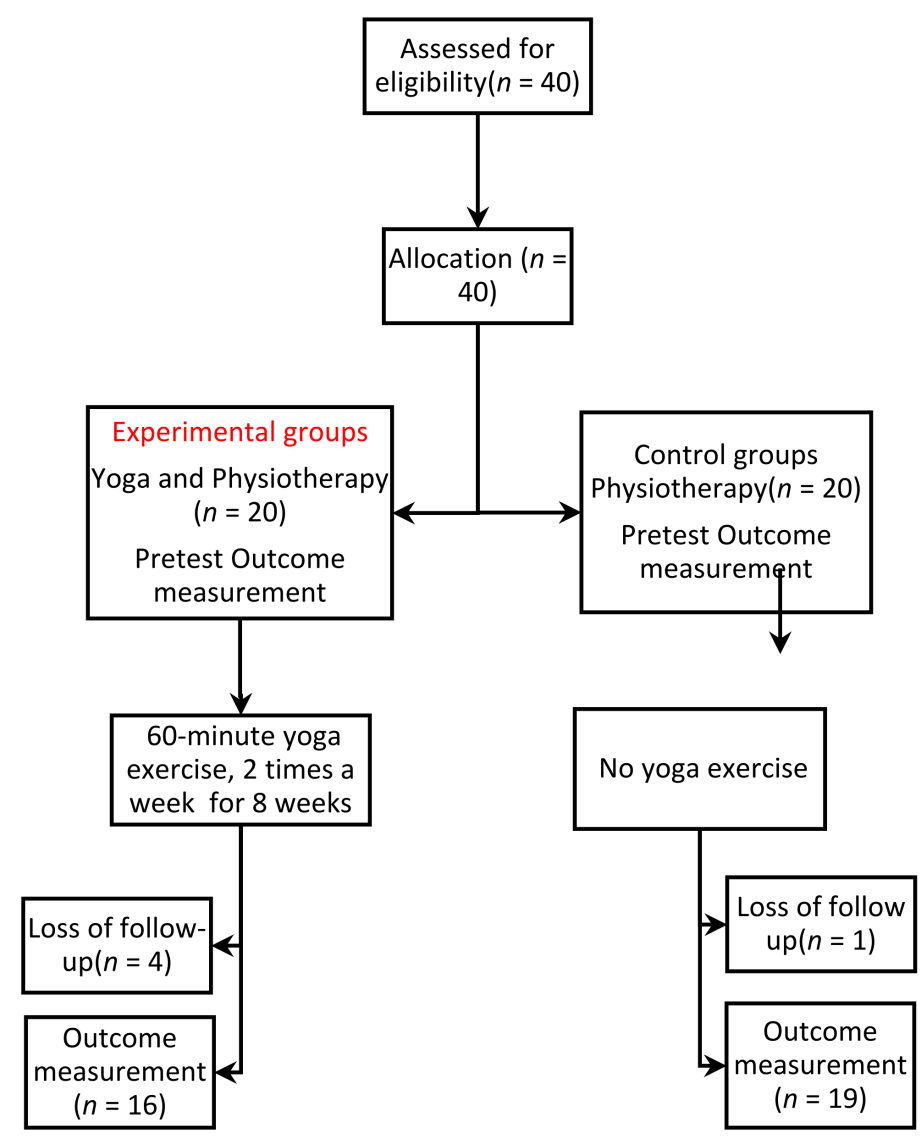

Figure 1. Flow diagram of the study.

Yoga Exercise Combined Standardized Rehabilitation Program (Intervention Group): In the intervention group, yoga was taught by a registered yoga therapist. A standard protocol was developed with $10 \mathrm{~min}$ of warm-up, $40 \mathrm{~min}$ of main activity, and $10 \mathrm{~min}$ cool-down exercises. All sessions focused on breathing, deep relaxation, mediation, posture, and trunk/limb stretching based on a study showed yoga improved balance in chronic stroke patients [15] (see Supplementary Materials Table S1-S3).

Standardized Rehabilitation Program (Control Group):All participants participated in the program based on the Taiwan Guideline for Stroke Rehabilitation [22] focused on dynamic balance exercises and weight-shift training given by the same therapists.

\subsection{Assessment of Outcome}

The outcome (depression and balance) were measured with the Taiwanese Depression Questionnaire (TDQ) [23] and Berg Balance Scale (BBS) [24] by the same therapist. (For TDQ: the lower the score, the better the mood. As for BBS: the higher the score, the better the balance.)

The TDQ is an 18-item questionnaire, and each item applies a 4-point scale for the response. It is a culturally specific self-rating instrument for screening of depression. Subjects are guided to rate each item on a scale from 0 to 3 based on "how often you felt during the past week". TDQ scores range from 0 to 54. Previous studies indicate good psychometric properties in the TDQ $[25,26]$. The cutoff scores for the screening of depression was 15 [27].

Balance was assessed with the Berg Balance Scale (BBS), which is the gold standard for functional balance testing [28]. It is a 14-item scale and can measure static and dynamic balance after stroke with good reliability and validity [28]. The total score is 56 points. The risk of falls in older adults was high when the score was less than 36 [29], and the 
risk increased by $6 \%$ to $8 \%$ with every one-point reduction within the range of 46 to 54 points [30].

\subsection{Statistical Analysis}

We performed statistical analyses using SPSS for Windows (Version 19.0, IBM Corp, Armonk, NY, USA). Continuous data are expressed as mean \pm standard deviation. The independent $t$-test was used to compare the differences between the two groups (indicated with dotted arrows in the figure). We analyzed the measured values before and after the treatment by paired $t$-tests (indicated with bold arrows in the figure). A $p$-value of less than 0.05 is considered to be statistical significant (indicated with an asterisk in the figure). The sample size was determined based on an effective size to detect differences in different groups. If we permitted a $5 \%$ chance of a type I error $(\alpha=0.05)$, with a power of $80 \%$, assuming the difference among the two groups was at least equal to the standard derivation, then approximately 32 patients would be required, while 35 patients completed the study. Subgroup analysis was performed on sex, brain lesion site and age.

\section{Results}

\subsection{Primary Analysis of the Effect for Adding Yoga}

Forty people enrolled initially with 20 to the intervention (yoga) group and 20 to the control group (Figure 1). In the yoga group, 16 completed the study. (One failed due to feeling exhausted, and three due to loss of follow-up thus being excluded). In the control group, 19 completed the study, and one loss of follow-up due to recurrent stroke. The completion rate of did not differ significantly. Age, sex, and brain lesion site (Table 1) were also similar. The TDQ score did not differ at baseline, whereas BBS scores were significantly better in the yoga group (Table 1). Overall, the TDQ of all patients decreased (improved) $(15.23 \pm 9.91$ to $11.71 \pm 8.66 ; p=0.001)$ and the BBS increased (improved) from $44.71 \pm 7.64$ to $46.60 \pm 7.46(p<0.001)$ after intervention.

Table 1. Comparison of baseline clinical and 8-week post-assessment of depression (Taiwanese Depression Questionnaire, TDQ) and balance (Berg Balance Scale, BBS), between control and experimental groups.

\begin{tabular}{|c|c|c|c|c|}
\hline & All $(n=35)$ & $\begin{array}{l}\text { With Yoga } \\
\quad(n=16)\end{array}$ & $\begin{array}{l}\text { Without Yoga } \\
\quad(n=19)\end{array}$ & $p$ \\
\hline Study completion rate, $-/+$ & $35 / 40$ & $16 / 20$ & $19 / 20$ & 0.151 \\
\hline \multicolumn{5}{|c|}{ Categorical variables, Chi-square test } \\
\hline Sex, female:male & $15: 20$ & $6: 10$ & 9:10 & 0.734 \\
\hline Stroke side, left:right ${ }^{\dagger}$ & $17: 17$ & $11: 5$ & $6: 12$ & 0.084 \\
\hline Age $<60$ :age $\geq 60$, years & 19:16 & $11: 5$ & $8: 11$ & 0.176 \\
\hline \multicolumn{5}{|c|}{ Continuous variables, $t$-test } \\
\hline Age & $59.0 \pm 10.10$ & $56.8 \pm 9.11$ & $60.9 \pm 10.743$ & 0.241 \\
\hline T onset (days) & $691.9 \pm 20.17$ & $560.6 \pm 538.57$ & $802.4 \pm 1153.00$ & 0.447 \\
\hline \multicolumn{5}{|c|}{ Taiwanese Depression Questionnaire (TDQ) score } \\
\hline Baseline TDQ & $15.23 \pm 9.91$ & $14.06 \pm 8.85$ & $16.21 \pm 10.86$ & 0.531 \\
\hline Post intervention TDQ & $11.71 \pm 8.66$ & $8.25 \pm 5.19$ & $14.63 \pm 9.99$ & $0.028 *$ \\
\hline The change of TDQ & $-3.51 \pm 5.84$ & $-5.81 \pm 6.13$ & $-1.57 \pm 4.94$ & 0.806 \\
\hline Paired $\mathrm{t}(p)$ & $0.001 *$ & $0.002 *$ & 0.181 & \\
\hline \multicolumn{5}{|c|}{ Berg Balance Scale (BBS) score } \\
\hline Baseline BBS & $44.71 \pm 7.64$ & $48.56 \pm 4.42$ & $41.47 \pm 8.01$ & $<0.001 *$ \\
\hline Post intervention BBS & $46.60 \pm 7.46$ & $51.13 \pm 4.25$ & $42.79 \pm 7.85$ & $<0.001$ * \\
\hline The change of BBS & $1.87 \pm 1.79$ & $2.56 \pm 1.96$ & $1.31 \pm 1.45$ & 0.029 * \\
\hline Paired $t$-test $(p)$ & $<0.001 *$ & $<0.001 *$ & $0.001 *$ & \\
\hline
\end{tabular}

Data are given as means \pm SD unless otherwise indicated. + One patient was eliminated in this analysis due to this patient suffered from bilateral stroke. ${ }^{*} p<0.05$, T onset: days after stroke. D0: for baseline TDQ; D1 for post-assessment TDQ; delta D: the change from D0 to D1. B0: for baseline BBS; B1 for post-assessment BBS; delta B: the change from D0 to D1. 
The TDQ scores improved significantly only in the yoga group (14.06 \pm 8.85 to $8.25 \pm 5.19, p=0.002)$. In contrast, patients in the control group had little improvement $(p=0.181)$ (Figure 2A) (bold black arrow). The baseline TDQ did not differ $(p=0.531)$. But the post-study TDQ was significantly lower $(8.25 \pm 5.19$ vs. $14.63 \pm 9.99, p=0.028)$ in the yoga group (Figure 2A) (Dotted arrow).
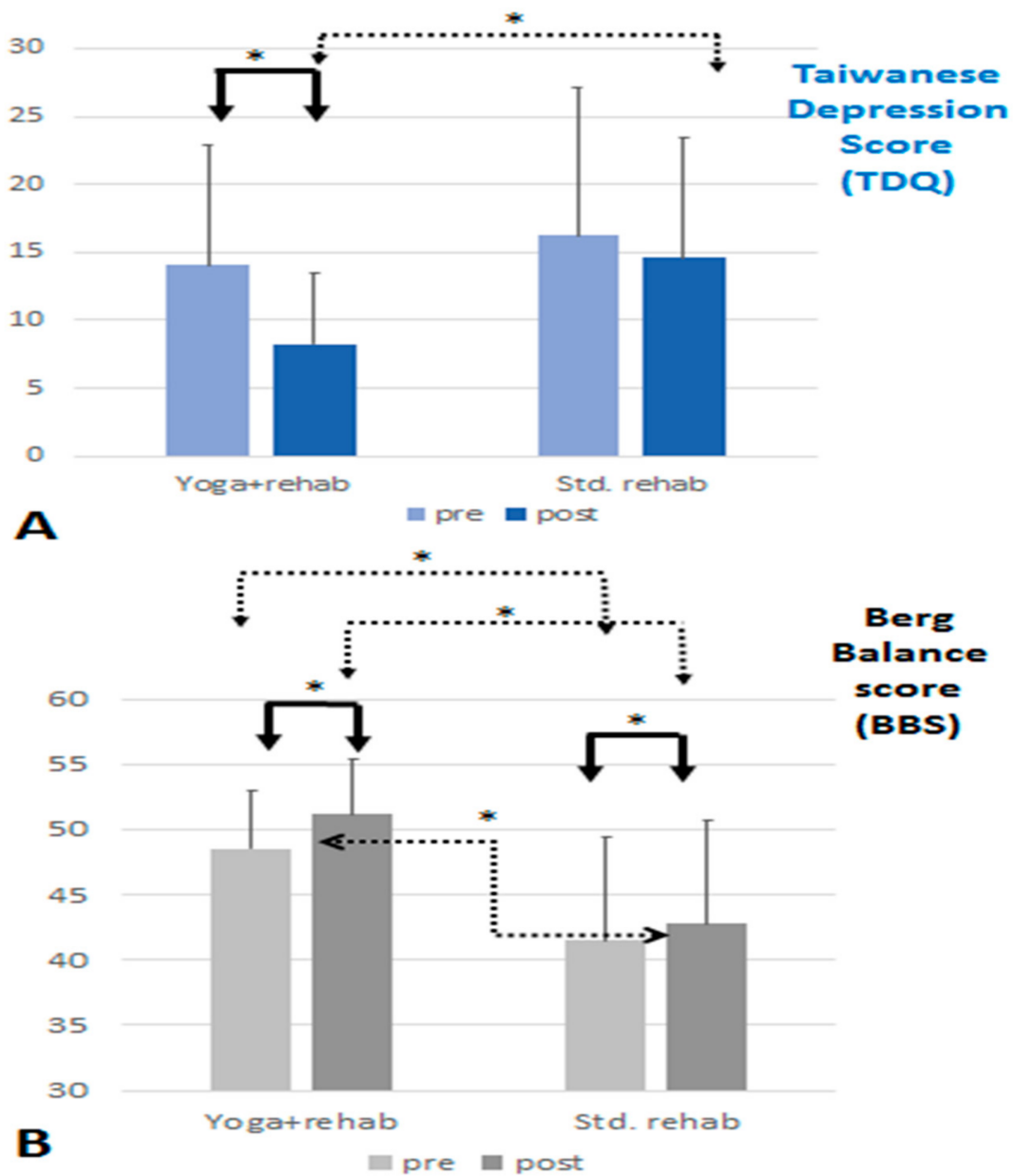

Figure 2. (A): Bold black arrows show TDQ score significant dropped (improved) in the yoga group after the intervention compared with their own baseline $(p=0.002)$. Dotted arrow showed the post intervention TDQ score is significantly lower in the yoga group compared to the control standard rehabilitation group. $(p=0.028)$. (B): Bold black arrows show BBS score significant increased (improved) in yoga $(p<0.001)$ and control group $(p=0.001)$ after the intervention compared with their own baseline BBS score. The dotted arrow shows the pre- and post-study values of the BBS in the yoga group are higher than that of the control group (both $p<0.001$ ) Screwed dotted arrow shows the post intervention increase of BBS score is significantly larger in the yoga group compared to the control standard rehabilitation group $(p=0.029)$. $\left({ }^{*}: p<0.05\right)$.

Both groups showed improvement in balance. The BBS score increased from $48.56 \pm 4.42$ to $51.13 \pm 4.25(p<0.001)$ in the yoga group, while from $41.47 \pm 8.01$ to $42.79 \pm 7.85$ $(p=0.001)$ (Figure 2B) for the control group. (Bold black arrows) Although the pre- and post-study BBS scores in the yoga group were higher (dotted arrows), the improvement in the yoga group is also significantly larger than that of the control group ( $2.56 \pm 1.96 \mathrm{vs}$. $1.31 \pm 1.45, p=0.029$ ) (Table 1) (Figure 2B) (screwed dotted arrow). 


\subsection{Subgroup Analysis}

The experiment group and control group were combined and divided by gender (female vs. male), brain lesion side (left vs. right) and age (age $<60$ vs. 60 or more) sequentially to see how these factors affected the result of rehabilitation (Table 2).

Table 2. Subgroup analysis for sex, lesion side, and age before and after the rehabilitation in comparison Taiwanese Depression Questionnaire (TDQ) scores and Berg Balance Scale (BBS) scores.

\begin{tabular}{|c|c|c|c|c|c|c|c|c|c|}
\hline $\begin{array}{l}\text { Subgroup } \\
\text { Variable }\end{array}$ & $\begin{array}{c}\text { Women } \\
n=15\end{array}$ & $\begin{array}{c}\text { Men } \\
n=20\end{array}$ & $p$ & $\begin{array}{c}\text { Left } \\
n=17\end{array}$ & $\begin{array}{l}\text { Right } \\
n=17\end{array}$ & $p$ & $\begin{array}{c}\text { Age }<60 \\
n=19\end{array}$ & $\begin{array}{c}\text { Age } \geq 60 \\
n=16\end{array}$ & $p$ \\
\hline $\begin{array}{c}\text { Age } \\
\text { (years) }\end{array}$ & $\begin{array}{c}60.88 \\
\pm 12.42\end{array}$ & $\begin{array}{c}57.64 \\
\pm 7.99\end{array}$ & 0.386 & $\begin{array}{c}55.79 \\
\pm 7.81\end{array}$ & $\begin{array}{c}62.06 \\
\pm 11.57\end{array}$ & 0.733 & $\begin{array}{l}51.48 \\
\pm 5.91\end{array}$ & $\begin{array}{c}68.00 \\
\pm 5.56\end{array}$ & $<0.001$ \\
\hline $\begin{array}{l}\text { T onset } \\
\text { (days) }\end{array}$ & $\begin{array}{c}426.67 \\
\pm 376.12\end{array}$ & $\begin{array}{c}376.12 \\
\pm 1146.20\end{array}$ & 0.103 & $\begin{array}{c}1002.76 \\
\pm 1212.40\end{array}$ & $\begin{array}{c}404.65 \\
\pm 358.96\end{array}$ & 0.60 & $\begin{array}{c}734.00 \\
\pm 951.33\end{array}$ & $\begin{array}{c}641.81 \\
\pm 910.08\end{array}$ & 0.773 \\
\hline \multicolumn{10}{|c|}{ Taiwanese Depression Questionnaire (TDQ) score } \\
\hline D0 & $\begin{array}{c}16.73 \\
\pm 9.18\end{array}$ & $\begin{array}{c}14.10 \\
\pm 10.51\end{array}$ & 0.445 & $\begin{array}{c}13.47 \\
\pm 9.28\end{array}$ & $\begin{array}{c}16.47 \\
\pm 10.61\end{array}$ & 0.387 & $\begin{array}{c}15.74 \\
\pm 8.93\end{array}$ & $\begin{array}{c}14.63 \\
\pm 11.23\end{array}$ & 0.746 \\
\hline D1 & $\begin{array}{c}12.93 \pm \\
8.10\end{array}$ & $\begin{array}{c}8.10 \\
\pm 9.16\end{array}$ & 0.479 & $\begin{array}{c}8.94 \\
\pm 5.68\end{array}$ & $\begin{array}{c}13.76 \\
\pm 10.26\end{array}$ & 0.102 & $\begin{array}{c}12.32 \\
\pm 7.97\end{array}$ & $\begin{array}{l}11.00 \\
\pm 9.64\end{array}$ & 0.661 \\
\hline Delta D & $\begin{array}{l}-3.80 \\
\pm 5.62\end{array}$ & $\begin{array}{l}-3.30 \\
\pm 6.13\end{array}$ & 0.806 & $\begin{array}{l}-4.52 \\
\pm 5.95\end{array}$ & $\begin{array}{l}-2.70 \\
\pm 5.87\end{array}$ & 0.376 & $\begin{array}{l}-3.42 \\
\pm 6.41\end{array}$ & $\begin{array}{l}-3.62 \\
\pm 5.28\end{array}$ & 0.920 \\
\hline Paired $\mathrm{t}(p)$ & $0.020 *$ & $0.027 *$ & & $0.006^{*}$ & 0.076 & & $0.032 *$ & $0.015 *$ & \\
\hline \multicolumn{10}{|c|}{ Berg Balance Scale (BBS) score (BBS) score } \\
\hline B0 & $\begin{array}{l}44.60 \\
\pm 8.16\end{array}$ & $\begin{array}{l}44.80 \\
\pm 7.08\end{array}$ & 0.939 & $\begin{array}{c}46.41 \\
\pm 6.21\end{array}$ & $\begin{array}{l}44.12 \\
\pm 7.34\end{array}$ & 0.333 & $\begin{array}{l}48.58 \\
\pm 4.77\end{array}$ & $\begin{array}{l}40.13 \\
\pm 7.55\end{array}$ & 0.001 * \\
\hline B1 & $\begin{array}{c}45.73 \\
\pm 8.53\end{array}$ & $\begin{array}{l}47.25 \\
\pm 7.05\end{array}$ & 0.569 & $\begin{array}{c}48.82 \\
\pm 6.24\end{array}$ & $\begin{array}{c}45.35 \\
\pm 7.80\end{array}$ & 0.162 & $\begin{array}{l}50.37 \\
\pm 4.65\end{array}$ & $\begin{array}{c}42.13 \\
\pm 8.18\end{array}$ & $0.002 *$ \\
\hline Delta B & $\begin{array}{c}1.13 \\
\pm 1.45\end{array}$ & $\begin{array}{c}2.45 \\
\pm 1.84\end{array}$ & $0.029 *$ & $\begin{array}{c}2.41 \\
\pm 1.90\end{array}$ & $\begin{array}{c}1.23 \\
\pm 1.48\end{array}$ & 0.053 & $\begin{array}{c}1.78 \\
\pm 1.96\end{array}$ & $\begin{array}{c}2.00 \\
\pm 1.63\end{array}$ & 0.735 \\
\hline Paired $\mathrm{t}(p)$ & 0.009 * & $<0.001 *$ & & $<0.001 *$ & 0.003 * & & 0.001 * & $<0.001 *$ & \\
\hline
\end{tabular}

${ }^{*} p<0.05$, T onset: days after stroke. D0: for baseline TDQ; D1 for post-assessment TDQ; delta D: the change from D0 to D1. B0: for baseline BBS; B1 for post-assessment BBS; delta B: the change from D0 to D1.

\subsubsection{Gender}

The mean age and the duration since stroke did not statistically differ by sex (Table 1). The TDQ scores improved after the study in both men and women. The TDQ scores dropped (improved) from $16.73 \pm 9.18$ to $12.93 \pm 8.10(p=0.020)$ for women and from $14.10 \pm 10.51$ to $8.10 \pm 9.16(p=0.027)$ for men (Figure 3A) (bold black arrow). For balance, the BBS score among all women improved from $44.60 \pm 8.16$ to $45.73 \pm 8.53(p=0.009)$ and from $44.80 \pm 7.08$ to $47.25 \pm 7.05$ among men $(p<0.001)$ (Figure 3B). Thus, rehabilitation was effective despite sex. However, significantly greater improvement in BBS was observed in men ( $p=0.029)$ (Figure 3B) (screwed dotted arrow). Balance among men seems to benefit more than that of women.

\subsubsection{Brain Lesion Side}

Further analysis of the stroke site in the brain is shown in Table 2 and illustrated in Figure 3B. For depression, patients with left-sided brain lesions showed significant improvement (TDQ scores decreased from $13.47 \pm 9.28$ to $8.94 \pm 5.68, p=0.006$ ) (Figure $3 \mathrm{C}$ ) (bold black arrow). In contrast, patients with right-sided brain lesions showed no significant improvement in TDQ $(p=0.076)$ (Figure 3C).

For balance, unlike depression, patients showed significant improvement despite the lesion site. Overall, BBS scores of patients with left-brain and right-brain lesions increased from $46.41 \pm 6.21$ to $48.82 \pm 6.24(p<0.001)$ and from $44.12 \pm 7.34$ to $45.35 \pm 7.80$ $(p=0.003)$, respectively (Figure 3D) (bold black arrow). In summary, TDQ scores for depression improved only in patients with left brain lesions, but balance improved in all subgroups despite the lesion site. 


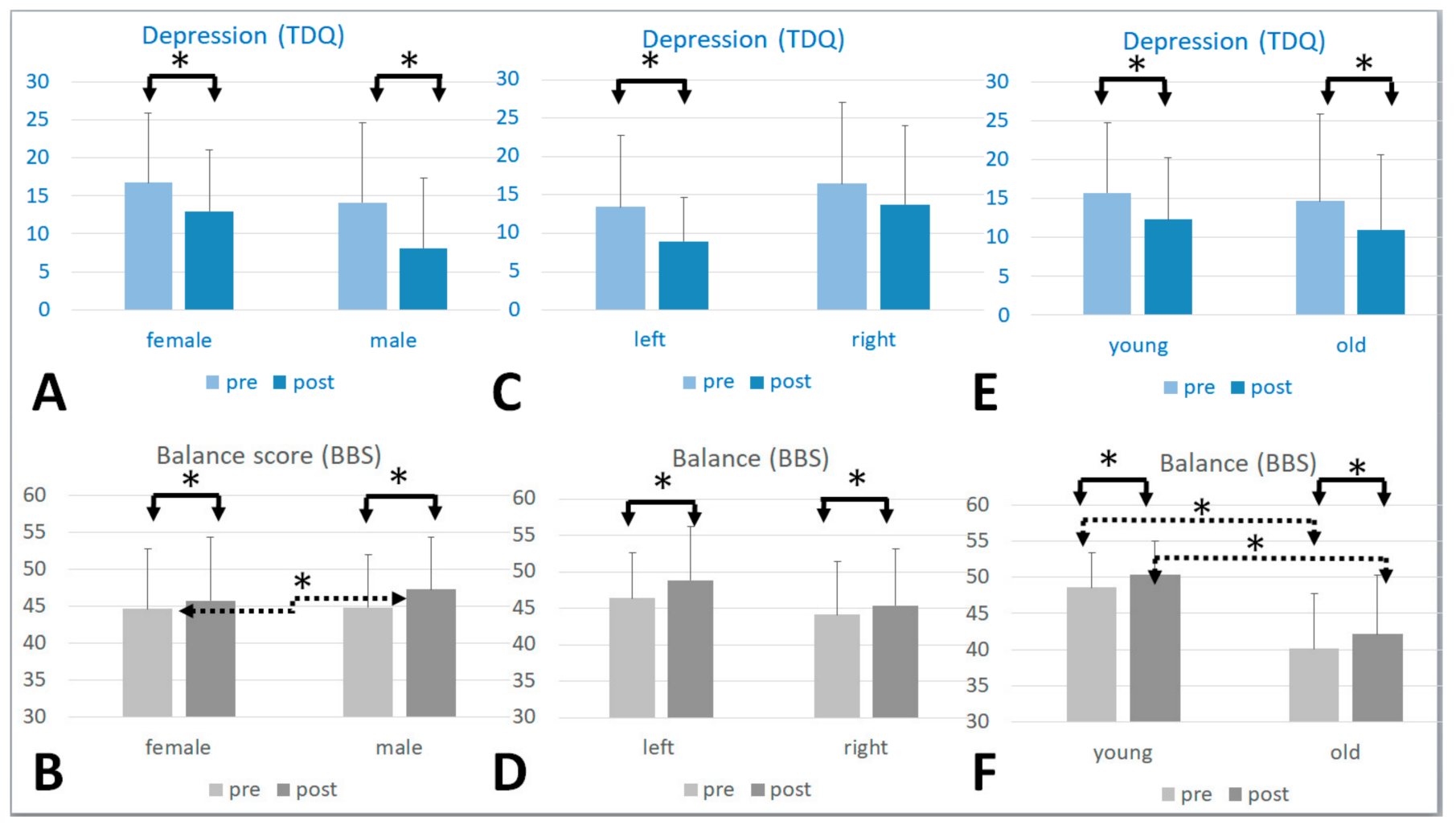

Figure 3. (A): Bold black arrow shows TDQ score significant dropped (improved) in the male and female groups after the intervention compared with their baseline TDQ score. (B): The improvement of TDQ is mainly contributed by the yoga groups in both genders. (C): Bold black arrow shows TDQ score significant dropped (improved) in the left brain lesion group after the intervention compared with their baseline. $(p=0.006)(D)$ : The improvement of TDQ is mainly contributed by patients with left brain lesion in the yoga groups. $(p=0.011)(\mathrm{E})$ : Bold black arrow shows TDQ score significant dropped (improved) in the young group $(p=0.032)$ and old group $(p=0.015)$ after the intervention compared with their baseline. (F): The improvement of TDQ is mainly contributed by young patients in the yoga groups $(p=0.010) .\left({ }^{*}: p<0.05\right)$.

\subsubsection{Age}

Table 2 also shows the age effect. We divided the patients by the age of 60 because the mean age is about 60 years $(55.79 \pm 7.81)$. Overall, depression improved in both the young and older groups. The TDQ score dropped from $15.74 \pm 8.93$ to $12.32 \pm 7.97(p=0.032)$ in the young and from $14.63 \pm 11.23$ to $11.00 \pm 9.64(p=0.015)$ in the older group (Figure 3E) (bold black arrow).

As for balance, both young and older patients benefitted from rehabilitation. Generally, the BBS score improved from $48.58 \pm 4.77$ to $50.3 \pm 4.65(p=0.001)$ in young patients and from $40.13 \pm 7.55$ to $42.13 \pm 8.18$ ( $p<0.001)$ among older patients (Bold black arrows). Additionally, the BBS scores of older patients were much lower than those of the younger ones. (Figure 3F) (dotted arrows).

\subsection{Factors Correlated with Balance}

Further analysis showed age is a big contributor to poor balance (linear regression for age vs. baseline BBS score, $p=0.005, \mathrm{R}^{2}=0.464$; age vs. post-intervention BBS score, $\left.p=0.006, \mathrm{R}^{2}=0.456\right)($ Figure 4$)$. 


\section{The correlation of age and balance}
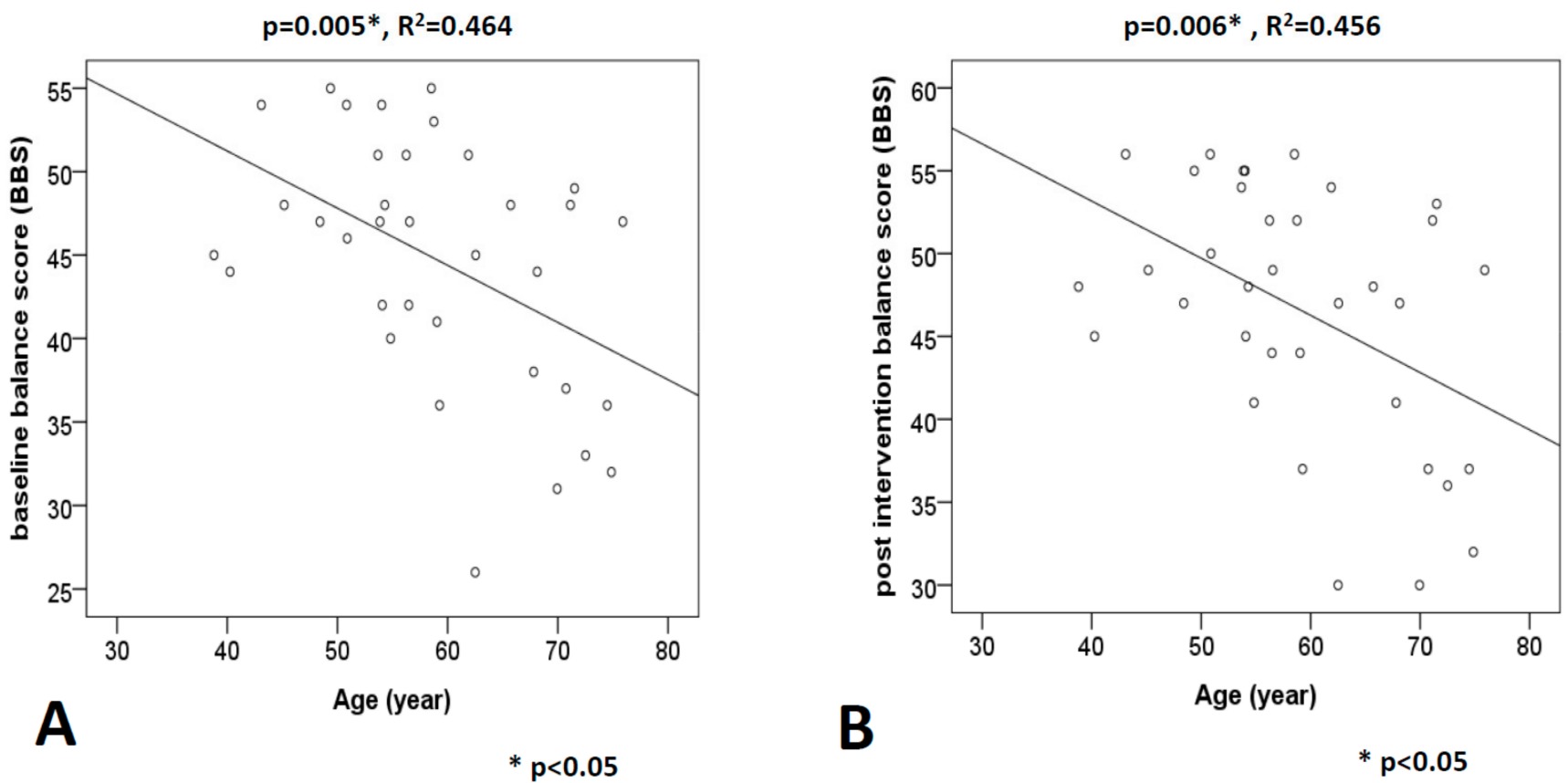

Figure 4. (A) Age is associated with lower baseline balance score (BBS) $\left(p=0.005, \mathrm{R}^{2}=0.464\right)$, (B) Age is associated with lower post intervention balance score (BBS) $\left.\left(p=0.006, \mathrm{R}^{2}=0.456\right)\left({ }^{*}: p<0.05\right)\right)$.

Although the baseline TDQ and BBS scores are not correlated $(p=0.25)$, the postintervention TDQ score is significantly correlated to the BBS score $(p=0.016)$ (Figure 5).

\section{The correlation of balance and depression}
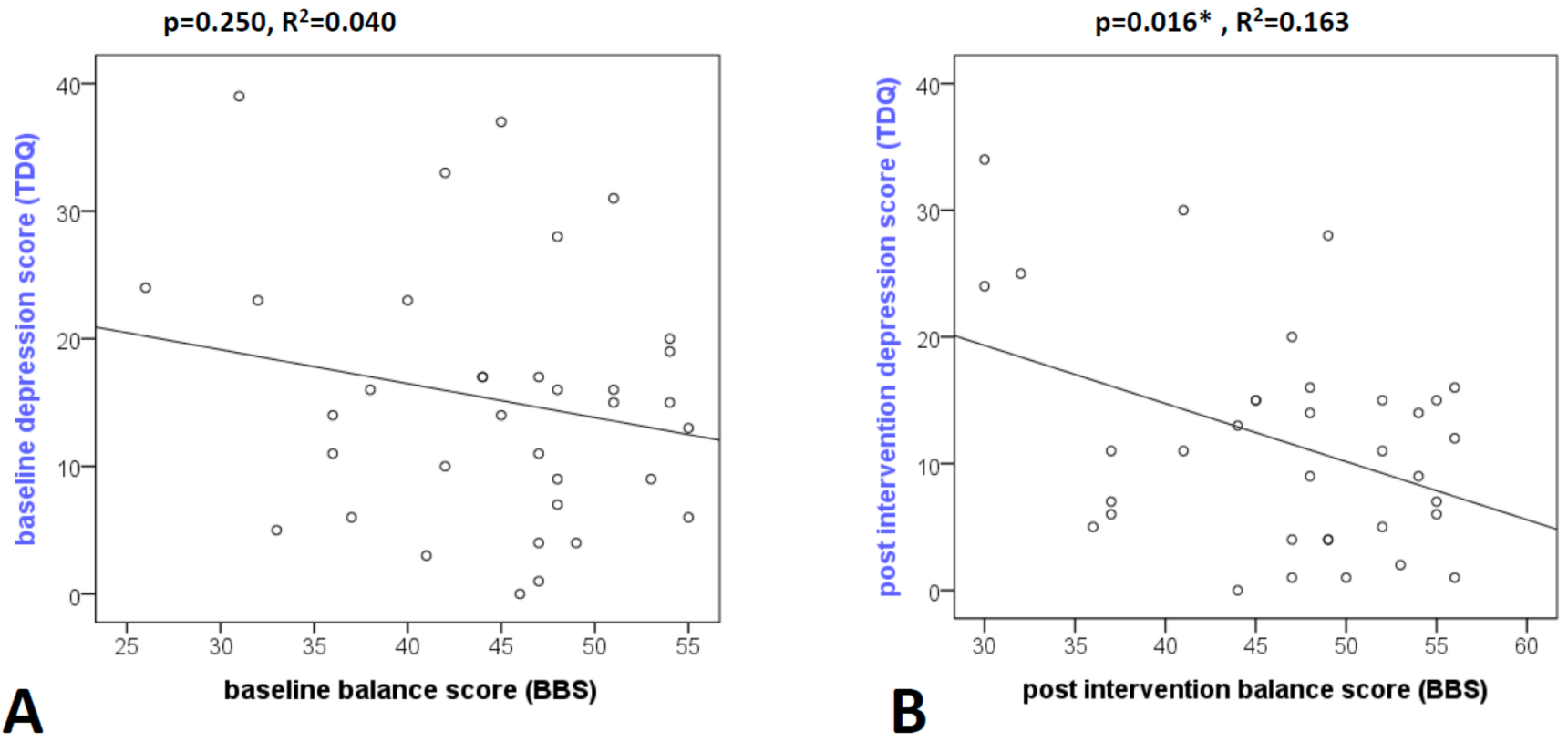

$* \mathrm{p}<0.05$

Figure 5. (A) Baseline balance score is not associated with baseline depression score (TDQ) ( $p=0.250$, $\left.\mathrm{R}^{2}=0.040\right),(\mathrm{B})$ post intervention balance is associated with post intervention depression score (TDQ) $\left(p=0.016, \mathbf{R}^{2}=0.163\right) .\left({ }^{*}: p<0.05\right)$. 


\section{Discussion}

All patients had significant improvement in depression and balance after rehabilitation (Table 1). Overall, a decrease in TDQ score $(p=0.001)$ and an increase in BBS score $(p<0.001)$ were noted. We found the TDQ scores of patients in the yoga group were much lower than those in the control group after the intervention while the baseline TDQ scores were similar (Figure 2A). Only patients in the yoga group showed significant improvement in depression after the intervention which indicates yoga provided anti-depression effect.

Because this was not a randomized trial, the baseline BBS score is much higher in the yoga group (with a better physical condition) compared to the control group even before intervention. BBS scores remained much higher after the intervention (Figure 2B). The reason may be that healthier people have higher intention to be volunteers for epidemiological research or a challenging task and have better survival rates than the general population, thereby producing bias referred to as the "healthy volunteer effect" [31]. Although both groups showed improvements in BBS scores (Figure 2B), the change of improvement in BBS was also significantly larger in the yoga group $(p=0.029)$. This finding indicates yoga still provided extra benefits compared to standard rehabilitation.

We compared the differences in the effects of rehabilitation on both sexes (Table 2 and Figure 3). Overall, we found that depression was significantly improved equally (Figure 3A). Unlike depression, balance showed a significantly greater improvement in men generally than in women $(p=0.029)$ (Figure 3B). One possible explanation is that men have poorer flexibility than women due to a lack of hormones such as estrogen or relaxin. Relaxin is known for relaxing the tendons and joints in pregnancy and delivery in women [32]. Yoga has been proven to improve flexibility [33], and flexibility is related to balance [34]. It may be that women have better flexibility in the first place, so the improvement of flexibility and balance after yoga may not be as good as man. In other words, the mind factor (anti-depression) of yoga is similar for both sexes but the body factor (balance) is quite different with better improvements in men.

The effect of brain lesion site is shown in Table 2 and Figure 3B. Only patients with left-sided brain lesions showed a significant improvement in depression (Figure 3C). This is probably due to left-sided brain lesion being associated with aphasia because the linguistic center is located the left brain while aphasia is highly associated with depression [35]. Yoga may lead to an improvement in aphasia [36]. Unlike depression, balance was uniformly improved in all subgroups of patients, despite of brain lesion side. These results are compatible with the brain structure whereby motor cortex is symmetrical, but the language center is located in the left brain [35].

Age is also an influencing factor. For patients younger than 60, depression $(p=0.032)$ and balance $(p=0.001)$ significantly improved. (Figure 3E). For older patients aged 60 or more, depression showed significant improvement $(p=0.015)$, and balance improved as well $(p<0.001)$ (Figure 3F). Therefore, rehabilitation is important for both young and older patients.

Further analysis of factors associated with balance, we found the BBS score is much lower in the older group, as age is significantly inverse related to the balance (Figure 4). This could be because young patients have better neuroplasticity and muscle power [37]. Aging is a big contributor to poor balance (linear regression for age vs. baseline BBS score, $p=0.005, \mathrm{R}^{2}=0.464$; age vs. post-intervention BBS score, $p=0.006, \mathrm{R}^{2}=0.456$ ) (Figure $4 \mathrm{~A}, \mathrm{~B}$ ). Nonetheless, age is not associated with depression (Age vs. baseline TDQ score, $p=0.551$; age vs. post-intervention BBS score, $p=0.439$ ). Therefore, old age may not guarantee depression.

On the other hand, although the baseline depression score (TDQ) and balance (BBS) scores are not correlated $(p=0.25)$, the post-intervention TDQ score is significantly correlated to the BBS score $(p=0.016)$. This may indicates that better post-intervention physical condition may contribute to a better quality of life and mood after completing the rehabilitation (Figure 5A,B). However, there are more factors other than age (such as gender, brain lesion side) affecting the outcome of rehabilitation. 
In summary, for the subgroup analysis of overall rehabilitation effect, we found both sexes benefited in depression and men benefited more in balance than women. Patients with left-brain lesions improved more in depression than those with right lesions after rehabilitation, while balance equally improved regardless of the lesion site. For patients under or above the age of 60 , depression and balance both significantly improved after rehabilitation. Older age was significantly related to poor balance but not depression. Post-intervention higher balance (BBS) score was significantly correlated to lower TDQ score and thus a better mood.

Our first limitation was that this was a pilot study with small recruitment number, but we still obtained many significant results. Second, the inclusion criteria limit each subject must be able to stand independently for $1 \mathrm{~min}$, which indicated participants were all relatively mildly functionally impaired. Whether the results can be applied to more disabled people is unknown. Third, in order to respect participants' will and their capability, our study was not randomized. (However, if done in a randomized manner, the completion rate could be much lower in the intervention group.) Also, the long-term effect after 8 weeks was not confirmed. A larger randomized controlled study with longer follow up period is necessary in the future. Finally, we should add one more group with standard rehabilitation of $300 \mathrm{~min}(5 \mathrm{~h})$ each week to see which group performs better. However, patients always get bored and become impatient during repetitive exercise in the real clinical setting. That is why we add recreational sport (such as yoga) as an adjuvant exercise because yoga is relaxing and interesting.

Because of the COVID-19 pandemic, group exercise may increase the infection risk. Whether remote video-assisted yoga training provides the same benefit as the current group exercise requires further research.

\section{Conclusions}

Generally, improvements were noted for balance in patients with standard rehabilitation but improvement in depression was only observed among patients when yoga was combined. Yoga provided more benefit for men than women in balance, for patients with left side brain lesion in depression, and for patients aged under or above 60 in both balance and depression. Older age was significantly related to poor balance but not depression. Post-intervention higher balance (BBS) score was significantly correlated to lower TDQ score and thus a better mood. Our study showed that combining yoga in the current standard rehabilitation is safe and has the potential to improve mood and balance, which provides useful information for stroke patients in tailor-made rehabilitation combing yoga.

Supplementary Materials: The following supporting information can be downloaded at: https:/ / www.mdpi.com/article/10.3390/app12020922/s1. Table S1: Standard stroke rehabilitation; Table S2: Yoga class schedule (16 yoga sessions) in each week; Table S3: Yoga pose.

Author Contributions: Y.-T.L. made substantial contributions to the conception and design; acquisition, analysis and interpretation of data; drafting of the manuscript. C.-H.L., H.-H.T., S.-Y.L. and C.-C.L. revised the manuscript critically for important intellectual content. C.C.H. and J.-C.Y. provided clinical care for the patient and critically revised the manuscript for important intellectual content. W.-S.L. and H.-L.C. served as primary consultants in the management of the patient and made substantial contributions to the conception and design; analysis and interpretation of data; drafting of the manuscript; and revising the manuscript critically for important intellectual content; and gave final approval of the version to be published. All authors have read and agreed to the published version of the manuscript.

Funding: This trial was supported by the Department of Physical Medicine and Rehabilitation, National Taiwan University Hospital Hsin-Chu Branch (Protocol No.: HCH-102-22), the Ministry of Science and Technology (MOST 103-2410-H-134-022-MY), Taiwan and Taipei City Hospital (TPCH108-27), and Department of Health of Taipei City Government (10901-62-023).

Institutional Review Board Statement: Institutional Review Board (IRB)/Ethics Committee approval was obtained before the trial began, and the study was conducted in full compliance with 
the Declaration of Helsinki. The study was approved by the Ethics Committee of National Taiwan University Hospital Hsin-Chu Branch, 201210006IRB. Clinical Trial Registration Information: Yoga Exercise for Improving Balance in Patients with Subacute \& Chronic Stroke, NCT01806922. URL: https:/ / clinicaltrials.gov/ct2/show / NCT01806922 (accessed on 11 February 2014).

Informed Consent Statement: Informed consent was obtained from all subjects involved in the study. Written informed consent has been obtained from the patient(s) to publish this paper.

Conflicts of Interest: The authors declare no conflict of interest. The funders had no role in the design of the study; in the collection, analyses, or interpretation of data; in the writing of the manuscript, or in the decision to publish the results.

\section{References}

1. Benjamin, E.J.; Blaha, M.J.; Chiuve, S.E.; Cushman, M.; Das, S.R.; Deo, R.; de Ferranti, S.D.; Floyd, J.; Fornage, M.; Gillespie, C.; et al. Heart Disease and Stroke Statistics-2017. Circulation 2017, 135, e146-e603. [CrossRef]

2. Pahlman, U.; Gutierrez-Perez, C.; Savborg, M.; Knopp, E.; Tarkowski, E. Cognitive function and improvement of balance after stroke in elderly people: The Gothenburg cognitive stroke study in the elderly. Disabil. Rehabil. 2011, 33, 1952-1962. [CrossRef] [PubMed]

3. Robinson, R.G.; Jorge, R.E. Post-Stroke Depression: A Review. Am. J. Psychiatry 2016, 173, 221-231. [CrossRef] [PubMed]

4. Tyson, S.F.; Hanley, M.; Chillala, J.; Selley, A.; Tallis, R.C. Balance disability after stroke. Phys. Ther. 2006, 86, 30-38. [CrossRef]

5. Hackett, M.L.; Pickles, K. Part I: Frequency of depression after stroke: An updated systematic review and meta-analysis of observational studies. Int. J. Stroke 2014, 9, 1017-1025. [CrossRef] [PubMed]

6. Hsieh, L.P.; Kao, H.J. Depressive symptoms following ischemic stroke: A study of 207 patients. Acta Neurol. Taiwan. 2005, 14, 187-190.

7. Simpson, L.A.; Miller, W.C.; Eng, J.J. Effect of stroke on fall rate, location and predictors: A prospective comparison of older adults with and without stroke. PLoS ONE 2011, 6, e19431. [CrossRef] [PubMed]

8. Young, S.N. How to increase serotonin in the human brain without drugs. J. Psychiatry Neurosci. 2007, 32, $394-399$.

9. Carek, P.J.; Laibstain, S.E.; Carek, S.M. Exercise for the treatment of depression and anxiety. Int. J. Psychiatry Med. 2011, 41, 15-28. [CrossRef]

10. Troeung, L.; Egan, S.J.; Gasson, N. A waitlist-controlled trial of group cognitive behavioural therapy for depression and anxiety in Parkinson's disease. BMC Psychiatry 2014, 14, 19. [CrossRef]

11. Aidar, F.J.; Jacó de Oliveira, R.; Gama de Matos, D.; Chilibeck, P.D.; de Souza, R.F.; Carneiro, A.L.; Machado Reis, V. A randomized trial of the effects of an aquatic exercise program on depression, anxiety levels, and functional capacity of people who suffered an ischemic stroke. J. Sports Med. Phys. Fitness 2018, 58, 1171-1177. [CrossRef] [PubMed]

12. Franklin, R.A.; Butler, M.P.; Bentley, J.A. The physical postures of yoga practices may protect against depressive symptoms, even as life stressors increase: A moderation analysis. Psychol. Health Med. 2018, 1-10. [CrossRef] [PubMed]

13. Ebnezar, J.; Nagarathna, R.; Yogitha, B.; Nagendra, H.R. Effects of an integrated approach of hatha yoga therapy on functional disability, pain, and flexibility in osteoarthritis of the knee joint: A randomized controlled study. J. Altern. Complementary Med. 2012, 18, 463-472. [CrossRef] [PubMed]

14. Bastille, J.V.; Gill-Body, K.M. A yoga-based exercise program for people with chronic poststroke hemiparesis. Phys. Ther. 2004, 84, 33-48. [CrossRef]

15. Schmid, A.A.; Van Puymbroeck, M.; Altenburger, P.A.; Schalk, N.L.; Dierks, T.A.; Miller, K.K.; Damush, T.M.; Bravata, D.M.; Williams, L.S. Poststroke balance improves with yoga: A pilot study. Stroke 2012, 43, 2402-2407. [CrossRef] [PubMed]

16. Immink, M.A.; Hillier, S.; Petkov, J. Randomized controlled trial of yoga for chronic poststroke hemiparesis: Motor function, mental health, and quality of life outcomes. Top. Stroke Rehabil. 2014, 21, 256-271. [CrossRef]

17. Hartley, L.; Dyakova, M.; Holmes, J.; Clarke, A.; Lee, M.S.; Ernst, E.; Rees, K. Yoga for the primary prevention of cardiovascular disease. Cochrane Database Syst. Rev. 2014, Cd010072. [CrossRef]

18. Anne, E.; Cox, S.U.-F.; Amy, N.; D'Hondt-Taylor, M. The role of state mindfulness during yoga in predicting self-objectification and reasons for exercise. Psychol. Sport Exerc. 2016, 22, 321-327. [CrossRef]

19. Tsai, H.-G.; Chang, T.-C.; Chen, H.-Y.; Chen, Y.-C.; Liu, C.-Y. The Application of YOGA Activity in Psychiatric Occupational Therapy. J. Taiwan Occup. Therapy Res. Pract. 2008, 4, 69-77. [CrossRef]

20. Maraka, S.; Jiang, Q.; Jafari-Khouzani, K.; Li, L.; Malik, S.; Hamidian, H.; Zhang, T.; Lu, M.; Soltanian-Zadeh, H.; Chopp, M.; et al. Degree of corticospinal tract damage correlates with motor function after stroke. Ann. Clin. Transl. Neurol. 2014, 1, 891-899. [CrossRef] [PubMed]

21. Jorgensen, H.S.; Nakayama, H.; Raaschou, H.O.; Vive-Larsen, J.; Stoier, M.; Olsen, T.S. Outcome and time course of recovery in stroke. Part II: Time course of recovery. The Copenhagen Stroke Study. Arch. Phys. Med. Rehabil. 1995, 76, 406-412. [CrossRef]

22. Der-Sheng, H.; Chia-Wei, L.; Lu, L.; Ming-Yen, H.; Chueh-Hung, W.; Huey-Wen, L.; Ke-Vin, C.; Shin-Liang, P.; Tyng-Guey, W.; Chein-Wei, C. Taiwan Guideline for Stroke Rehabilitation. Taiwan J. Phys. Med. Rehabil. 2016, 44, 1-9. [CrossRef]

23. Lee, Y.; Yang, M.J.; Lai, T.J.; Chiu, N.M.; Chau, T.T. Development of the Taiwanese Depression Questionnaire. Change Gung Med. J. 2000, 23, 688-694. 
24. Berg, K.; Wood-Dauphinee, S.; Williams, J.I. The Balance Scale: Reliability assessment with elderly residents and patients with an acute stroke. Scand. J. Rehabil. Med. 1995, 27, 27-36. [PubMed]

25. Huang, Y.C.; Hsu, S.T.; Hung, C.F.; Wang, L.J.; Chong, M.Y. Mental health of caregivers of individuals with disabilities: Relation to Suicidal Ideation. Compr. Psychiatry 2018, 81, 22-27. [CrossRef]

26. Su, S.F.; Chang, M.Y.; He, C.P. Social Support, Unstable Angina, and Stroke as Predictors of Depression in Patients With Coronary Heart Disease. J. Cardiovasc. Nurs. 2018, 33, 179-186. [CrossRef]

27. Lee, Y.; Wu, Y.-S.; Chien, C.-Y.; Fang, F.-M.; Hung, C.-F. Use of the Hospital Anxiety and Depression Scale and the Taiwanese Depression Questionnaire for screening depression in head and neck cancer patients in Taiwan. Neuropsychiatr. Dis. Treat. 2016, 12, 2649-2657. [CrossRef]

28. Langley, F.A.; Mackintosh, S.F.H. Functional balance assessment of older community dwelling adults: A systematic review of the literature. Int. J. All. Health Sci. Pract. 2007, 5, 1-11. [CrossRef]

29. Berg, K.O.; Wood-Dauphinee, S.L.; Williams, J.I.; Maki, B. Measuring balance in the elderly: Validation of an instrument. Can. J. Public Health 1992, 83 (Suppl. S2), S7-S11.

30. Maeda, N.; Kato, J.; Shimada, T. Predicting the probability for fall incidence in stroke patients using the Berg Balance Scale. J. Int. Med. Res. 2009, 37, 697-704. [CrossRef]

31. Froom, P.; Melamed, S.; Kristal-Boneh, E.; Benbassat, J.; Ribak, J. Healthy volunteer effect in industrial workers. J. Clin. Epidemiol. 1999, 52, 731-735. [CrossRef]

32. Hansen, M.; Kjaer, M. Sex Hormones and Tendon. Adv. Exp. Med. Biol. 2016, 920, 139-149. [CrossRef]

33. Bucht, H.; Donath, L. Sauna Yoga Superiorly Improves Flexibility, Strength, and Balance: A Two-Armed Randomized Controlled Trial in Healthy Older Adults. Int. J. Environ. Res. Public Health 2019, 16, 3721. [CrossRef] [PubMed]

34. Overmoyer, G.V.; Reiser, R.F., 2nd. Relationships between lower-extremity flexibility, asymmetries, and the $Y$ balance test. J. Strength Cond. Res. 2015, 29, 1240-1247. [CrossRef]

35. Ashaie, S.A.; Hurwitz, R.; Cherney, L.R. Depression and Subthreshold Depression in Stroke-Related Aphasia. Arch. Phys. Med. Rehabil. 2019, 100, 1294-1299. [CrossRef]

36. Lynton, H.; Kligler, B.; Shiflett, S. Yoga in stroke rehabilitation: A systematic review and results of a pilot study. Top. Stroke Rehabil. 2007, 14, 1-8. [CrossRef] [PubMed]

37. Tolahunase, M.R.; Sagar, R.; Faiq, M.; Dada, R. Yoga- and meditation-based lifestyle intervention increases neuroplasticity and reduces severity of major depressive disorder: A randomized controlled trial. Restor. Neurol. Neurosci. 2018, 36, 423-442. [CrossRef] [PubMed] 